\title{
Secretion of tissue inhibitors of matrix metalloproteinases by human fetal membranes, decidua and placenta at parturition
}

\author{
S C Riley, R Leask, F C Denison, K Wisely, A A Calder and \\ D C Howe
}

Department of Obstetrics and Gynaecology, Centre for Reproductive Biology, University of Edinburgh, Edinburgh, UK

(Requests for offprints should be addressed to S C Riley, Department of Obstetrics and Gynaecology, Centre for Reproductive Biology, University of Edinburgh, 37 Chalmers Street, Edinburgh EH3 9EW, UK)

\begin{abstract}
At parturition, breakdown of extracellular matrix in the fetal membranes may play a part in the rupture of the membranes and in the aetiology of premature rupture, in addition to having a regulatory role in the cell-cell interactions and signalling at the feto-maternal interface to stimulate myometrial contractility. The matrix metalloproteinases (MMPs) are important enzymes for the breakdown of extracellular matrix and their activity is regulated by a family of endogenous inhibitors, the tissue inhibitors of matrix metalloproteinases (TIMPs). At parturition, alteration in the balance between MMPs and TIMPs may mediate this extracellular matrix breakdown during rupture of fetal membranes. The aims of this study were to determine if the intrauterine secretion of TIMPs changes at labour, and to characterise their cellular sources. A broad range of TIMP activities (27-30 kDa, $24 \mathrm{kDa}$ and $21 \mathrm{kDa}$ ) were detected by reverse zymography in term amniotic fluid. There was a significant $(P<0 \cdot 05)$ decrease in the
\end{abstract}

amount of TIMPs in amniotic fluid and their release with the onset of labour. The TIMPs were characterised by immunoblot as TIMPs-1, $-2,-3$ and -4 . High levels of TIMPs were secreted by explants of chorio-decidua, decidua parietalis and placenta, with less being released by amnion. Immunolocalisation studies revealed a specific distribution pattern for each of the TIMP isoforms. Trophoblast cells of chorion laeve, decidua parietalis and placental syncytiotrophoblast demonstrated specific immunoreactivity for all four isoforms. TIMPs were also found bound to selective regions of extracellular matrix. The decrease in TIMPs during labour may permit increased breakdown of extracellular matrix in the fetal membranes and decidua at parturition, thus altering cell signalling at the feto-maternal interface and facilitating membrane rupture.

Journal of Endocrinology (1999) 162, 351-359

\section{Introduction}

Characteristically in uncomplicated labour, the fetal membranes rupture shortly before the fetus is born (Parry \& Strauss 1998). The site at which the membranes rupture is morphologically distinct, and it is believed that this zone of altered morphology develops and enlarges some time before labour begins (Malak \& Bell 1994). The tissue remodelling associated with the zone of altered morphology almost certainly is a consequence of the secretion and activation of matrix metalloproteinase (MMP) enzymes, which act to break down the supporting extracellular matrix. In human and rat fetal membranes, an increase in MMP-9 activity has been demonstrated at the time of labour (Vadillo-Ortega et al. 1990, Lei et al. 1995, Riley et al. 1996), and extracellular matrix proteins in the fetal membranes, such as oncofetal fibronectin, can be detected in cervical mucus with the onset of labour (Malak et al. 1996, Goldenberg et al. 1997). MMPs may also contribute to labour by activating cytokines such as

tumour necrosis factor $\alpha$ (TNF $\alpha)$ (McGeehan et al. 1994), releasing stimulatory signals bound to the extracellular matrix (Lala \& Hamilton 1996) and by changing cellular signalling through uncoupling from matrix (Cross et al. 1994, Damsky et al. 1994). Finally, breakdown of the extracellular matrix allows the placenta and fetal membranes to separate from the uterus (Hulboy et al. 1997).

The activity of secreted MMPs is restricted by locally produced tissue inhibitors of metalloproteinases (TIMPs), of which, to date, four have been identified (Hulboy et al. 1997). MMP activity is inhibited by the formation of a $1: 1$ complex with TIMP. When an increase in metalloproteinase activity is measured, such as in labour, it is possible that this increase is due to increased secretion of MMPs, or to decreased secretion of TIMPs. The endometrium expresses TIMPs-1, -2 and -3 during the menstrual cycle (Zhang \& Salamonsen 1997), and TIMPs-1, -2 and -3 have been identified in placenta (Waterhouse et al. 1993, Bryant-Greenwood \& Yamamoto 
1995, Ruck et al. 1996). Production of TIMP-4 by intrauterine tissues has not been examined. However, relatively little is known about the contribution made by TIMPs to remodelling of the fetal membranes or the feto-maternal interface at labour. In this study, we have characterised the changes in secretion of TIMPs into amniotic fluid that occur in labour, and identified the predominant tissue and cellular sites of secretion of TIMPs in the fetal membranes, decidua and placenta at term.

\section{Materials and Methods}

\section{Tissue and sample collection}

Amniotic fluid was collected from women at term (>37 weeks) at elective caesarean section (not in labour; $n=15$ ) and after vaginal delivery from women with spontaneous onset of labour $(n=15)$. All samples were stored at $-20{ }^{\circ} \mathrm{C}$ before measurement of TIMPs. Tissues were collected at term immediately after either elective $(n=8)$ or emergency caesarean section in labour $(>4 \mathrm{~cm}$ cervical dilatation; sustained contractions for more than $4 \mathrm{~h} ; n=7$ ), undertaken for failure to progress. At the time of delivery, a clip was placed on the membranes overlying the cervical region to permit orientation. For immunohistochemistry, the following tissues were collected: fetal membranes from the fundal region remote from the placental edge; a cross-section of placenta from placental plate to decidua basalis from a centrally located cotyledon; decidua parietalis from the uterine aspect of the fundus. Tissues were fixed in 10\% neutral buffered formalin for $24 \mathrm{~h}$, then washed before being embedded in paraffin. For explant culture, all tissues used were collected at term elective caesarean section. Tissues were placed into sterile phosphate-buffered saline (PBS) containing heparin $(10 \mathrm{U} / \mathrm{ml})$ for transport to the laboratory. Procedures were approved by the Lothian Research Ethics Committee and informed written consent was obtained from all patients.

\section{Culture of tissue explants and trophoblast and fibroblast cells of chorion laeve}

Tissue explants were maintained in culture as described previously (Brennand et al. 1995). Discs of amnion (12 mm diameter; wet weight 8-15 $\mathrm{mg}$ ) and chorion laeve with adherent decidua ( $9 \mathrm{~mm}$ diameter; $15-25 \mathrm{mg}$ ) were prepared using a cork borer, and pieces of villous placental tissue (20-30 mg; from the core of centrally located cotyledons) and decidua parietalis $(20-30 \mathrm{mg}$; from the uterine aspect) were placed on absorbent capillary matting. These tissues were maintained in culture in serum-free medium (RPMI 1640 supplemented with insulin and transferrin $(5 \mu \mathrm{g} / \mathrm{ml})$, sodium selenite $(5 \mathrm{ng} / \mathrm{ml}$; all chemicals from Sigma Chemical Co., St Louis, MO, USA, unless stated otherwise), penicillin $(50 \mathrm{U} / \mathrm{ml})$ and strepto- mycin $(50 \mu \mathrm{g} / \mathrm{ml}$; Gibco, Paisley, Strathclyde, UK) in a water-saturated air-5\% $\mathrm{CO}_{2}$ atmosphere at $37^{\circ} \mathrm{C}$. Culture medium was collected after $24 \mathrm{~h}$.

Chorion trophoblast cells were prepared for culture by dispersion with trypsin-containing DNAase, as described previously (Kelly et al. 1997). Cells were maintained in culture for $48 \mathrm{~h}$ in the same medium (except that it was supplemented with 10\% fetal calf serum (FCS); Gibco) and conditions as described for the explants. Medium with serum omitted was then replaced and samples were collected for assay after a further $24 \mathrm{~h}$ of culture. To establish cultures of chorion laeve fibroblasts, the trophoblast cell preparation was maintained in culture (RPMI 1640 medium supplemented with 10\% FCS, $2 \mathrm{mM}$ L-glutamine, $50 \mu \mathrm{g} / \mathrm{ml}$ streptomycin, $20 \mu \mathrm{g} / \mathrm{ml}$ gentamycin and $50 \mathrm{IU}$ penicillin; Gibco). The population of fibroblasts were permitted to overgrow until they reached confluence. These fibroblasts were passaged, and maintained in medium containing 10\% FCS for $24 \mathrm{~h}$, to allow adherence to the plate. Culture medium was then aspirated and replaced with serum-free medium, which was sampled at $24 \mathrm{~h}$ for measurement of TIMPs.

Preparations of trophoblast cells were more than 90\% positive for the epithelial cell marker, cytokeratin, and less than $5 \%$ positive for the lymphoid cell marker, CD 45 , and the fibroblast cell marker, vimentin. Fibroblast cells were more than 95\% positive for vimentin, and phenotypically normal. All conditioned medium was stored at $-20{ }^{\circ} \mathrm{C}$ before analysis.

\section{Detection of TIMPs activity by reverse zymography}

The activity of TIMPs was detected by reverse zymography as described previously, using a commercially available kit (University Technologies Inc., Calgary, Canada) with some minor adaptations (Hampton et al. 1995). Culture medium samples were lyophilised and reconstituted in $0 \cdot 1 \%$ SDS in $\mathrm{H}_{2} \mathrm{O}$. Using a minigel apparatus, amniotic fluid $(7 \cdot 5 \mu \mathrm{l})$ and culture medium samples were separated by molecular weight by PAGE, using $12 \%$ gels containing gelatin $(1 \mathrm{mg} / \mathrm{ml})$ and a preparation of MMP-2 (conditioned medium from BHK-21 cells that constitutively express MMP-2; University Technologies Inc.). The amount of culture medium sample loaded was standardised to give an output equivalent to $5 \mathrm{mg}$ tissue explant or $10^{4}$ cells in culture. Gels were washed in a wash buffer (50 mM Tris, $5 \mathrm{mM} \mathrm{CaCl}$, 2.5\% (v/v) Triton X-100) for $2.5 \mathrm{~h}$ at $23{ }^{\circ} \mathrm{C}$, then incubated in reverse zymography digestion buffer (wash buffer excluding Triton X-100) at $37^{\circ} \mathrm{C}$ for $17 \mathrm{~h}$. Gels were then stained in staining buffer (0.5\% Coomassie blue R250 (BioRad, Hemel Hempstead, UK) in 30\% methanol-10\% glacial acetic acid) and destained (in staining buffer without the Coomassie blue). The inhibitory activity of TIMPs on the degradation of substrate by MMP-2 appeared as dark bands against a lighter background. TIMPs were identified and 
characterised by comparison with molecular weight markers (BioRad) and control standard solutions containing mouse TIMP-1 and TIMP-2 and the glycosylated and unglycosylated forms of TIMP-3 (University Technologies Inc.), and recombinant human TIMP-2 (Calbiochem, Nottingham, UK) to confirm identity. Analysis of samples by PAGE with gelatin substrate omitted demonstrated no significant detectable underlying protein staining at the molecular weights at which TIMPs were observed, demonstrating the specificity of the TIMP activity.

\section{Immunoblot for detection of TIMP proteins}

Samples of culture medium were dialysed (against $\mathrm{H}_{2} \mathrm{O}$ for $17 \mathrm{~h}$ at $23^{\circ} \mathrm{C}$; retention size $>12 \mathrm{kDa}$ ), lyophilised and reconstituted in $0 \cdot 1 \%$ SDS in $\mathrm{H}_{2} \mathrm{O}$. Samples were separated according to molecular weight by PAGE (12\% gels). The amount loaded was $20 \mu \mathrm{l}$ amniotic fluid or, for in vitro outputs, an amount standardised to be equivalent to $10 \mathrm{mg}$ tissue explant or $2 \times 10^{4}$ cells in culture. The separated proteins were transferred by wet blotting to nitrocellulose membranes. The membrane was preincubated over night with blocking solution $(5 \%$ bovine serum albumin or non-immune goat serum (Scottish Antibody Production Unit, Carluke, Scotland) in PBS) before application of the primary antibody. The antibodies used were affinitypurified rabbit polyclonal antibodies raised against synthetic peptides based on the human sequences of TIMPs-1, -2, -3 (Triple Point Biologics, Forest Grove, OR, USA) and -4 (Chemicon International Ltd, Harrow, UK). Recombinant TIMP-2 was also used as a standard (Calbiochem). The primary antibody was detected using a biotinylated goat anti-rabbit antibody and an avidin-peroxidase complex that was visualised using the chromagen, 3,3'-diaminobenzidine (Vector Labs, Burlinghame, CA, USA), as chromagen with $\mathrm{Ni}^{2+}$, according to the manufacturer's instructions.

\section{Localisation of TIMPs by immunohistochemistry}

Immunoreactive TIMPs-1, $-2,-3$ and -4 were localised in tissues using techniques described previously (Riley et al. 1991). In brief, tissue sections ( $5 \mu \mathrm{m})$ mounted on silanecoated slides were dewaxed and rehydrated, and the endogenous peroxidase activity inhibited by incubation in $\mathrm{H}_{2} \mathrm{O}_{2}$ (3\% solution in $\mathrm{H}_{2} \mathrm{O}$ for $20 \mathrm{~min}$ ). Sections were washed extensively and a blocking step applied (5\% normal goat serum; $30 \mathrm{~min}$ ), followed by the primary antibody. The antibodies used were the same as described for the Western blot analyses, in optimum dilutions determined in preliminary experiments as TIMP-1, $1:$ 500; TIMP-2, $1:$ 1000; TIMP-3, $1:$ 4000; TIMP-4, $1: 5000$. They were applied to consecutive sections that were incubated for $17 \mathrm{~h}$ at $4{ }^{\circ} \mathrm{C}$ in a humidified atmosphere. Epithelial and epithelial-derived cells (e.g. trophoblasts) were identified using a rabbit polyclonal antibody to cytokeratin (raised against bovine muzzle cytokeratin; broad spectrum screen, Dako Ltd, High Wycombe, Bucks, UK), as described previously (Riley et al. 1991). The primary antibody was detected and visualised using the same detection system described above for the immunoblot, except that $\mathrm{Ni}^{2+}$ enhancement was omitted (specific positive immunoreactivity appears brown). Sections were counterstained with haematoxylin, dehydrated, mounted, and visualised by light microscopy.

\section{Data analysis}

The presence of TIMPs in gels was analysed by transmission densitometry (G-700 densitometer, BioRad) and relative intensities of equal areas were compared using integrated software (Quantity One, BioRad). All densitometric assessments of reverse zymogram gels were performed within the optical density range of sensitivity (i.e. non-saturated pixels). Abundance of protein on immunoblots was determined by reflectance densitometry and analysed with the same software. Densitometric readings were analysed by ANOVA. Significance was taken when $P<0 \cdot 05$.

\section{Results}

\section{TIMPs in amniotic fluid}

In amniotic fluid, reverse zymography detected a broad spectrum of TIMP activity. These TIMP activities were detected as three predominant bands with molecular weights of 27-30, 24 and $21 \mathrm{kDa}$ (Fig. 1). The $27-30 \mathrm{kDa}$ band of activity consists of TIMP-1, glycosylated TIMP-3 and TIMP-4, which all have similar molecular weights and cannot be differentiated by reverse zymography; the $24 \mathrm{kDa}$ band contains unglycosylated TIMP-3 and the $21 \mathrm{kDa}$ band, TIMP-2. Immunoblot for TIMP-4 was used to characterise further which TIMPs proteins were present in the $27-30 \mathrm{kDa}$ band; this showed that TIMP-4 was present in amniotic fluid, but only in relatively low abundance (Fig. 2b). Densitometric analysis demonstrated that, in amniotic fluid, there was a significant $(P<0 \cdot 05)$ decrease in the overall relative amounts of TIMP activities of all three bands, corresponding to TIMPs-1, -2 and -3 , at elective caesarean section, compared with spontaneous delivery (Fig. 1b).

\section{Production of TIMPs by fetal membranes, decidua and placenta}

The intrauterine sources of TIMPs were determined by measuring TIMP activities by reverse zymography in culture medium conditioned by explants of amnion, chorion laeve with adherent decidua, placenta and decidua 


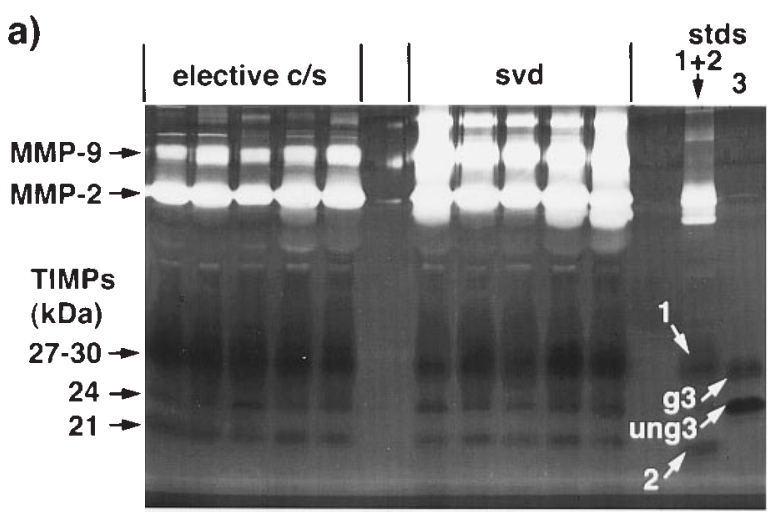

b)

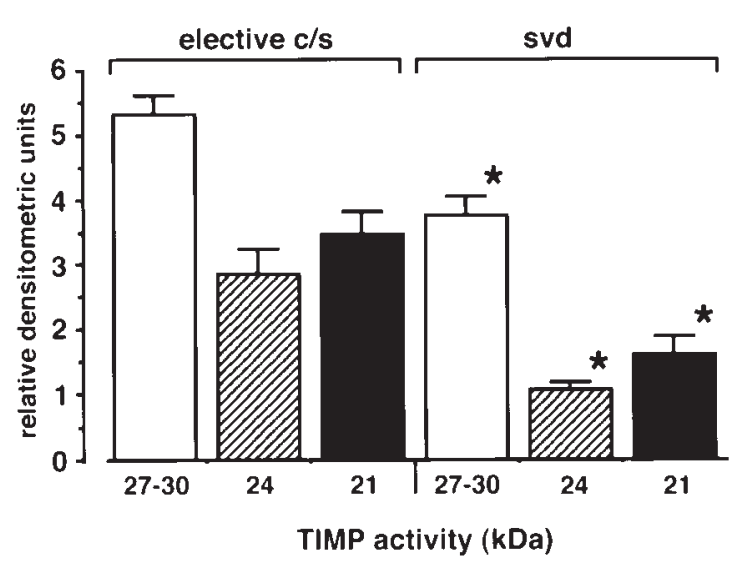

Figure 1 a) Representative reverse zymography gel demonstrating the presence of TIMPs activity (visualised as darker bands) in amniotic fluid ( $20 \mu \mathrm{l}$ each sample) collected at term (37-41 weeks gestation) after elective caesarean section (c/s) and after active labour (svd). TIMP activities are visualised as three predominant bands at 27-30 kDa, $24 \mathrm{kDa}$ and $21 \mathrm{kDa}$. These TIMP activities align with standards (stds; indicated by arrows) to TIMP-1 (1; $30 \mathrm{kDa})$ and TIMP-2 (2; $21 \mathrm{kDa}$; standard 1+2) and TIMP-3 (g3 = glycosylated form of $30 \mathrm{kDa}$; ung $3=$ unglycosylated form at $24 \mathrm{kDa}$; standard 3). Gelatinase activity is also visualised as white (clear) bands at higher molecular weights, corresponding to MMP-2 (72 kDa latent pro-form predominates; $66 \mathrm{kDa}$ active form) and MMP-9 (92 kDa latent pro-form). b) Relative densitometric analysis (mean \pm S.E.M.; $n=15$ ) of TIMP activity in amniotic fluid at 27-30 kDa (corresponding to TIMP-1, glycosylated form of TIMP-3 and TIMP-4; open bars), 24 kDa (unglycosylated TIMP-3; hatched bars) and 21 kDa (TIMP-2; solid bars). *Significantly $(P<0 \cdot 05)$ lower amounts of the corresponding TIMP activity in amniotic fluid collected after active labour (svd) compared with at elective caesarean section $(\mathrm{c} / \mathrm{s})$.

parietalis collected from the myometrial aspect (Fig. 3a). All tissues were collected after elective caesarean section at term. These tissues secreted a wide range of TIMPs with activity at $21,24,27-30 \mathrm{kDa}$, indicating the presence of all TIMP family members. Immunoblot analysis of proteins confirmed that immunoreactive TIMP-4 at $29 \mathrm{kDa}$ was secreted by all tissue types (Fig. 2a). Furthermore, explants of chorion laeve with adherent decidua parietalis a) explants

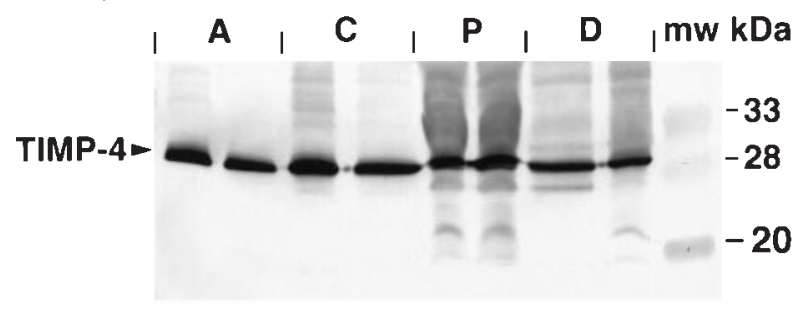

b) amniotic fluid

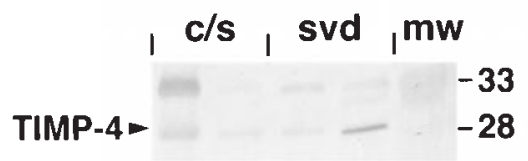

Figure 2 Characterisation by immunoblot analysis demonstrating the presence of TIMP-4. a) Secretion of TIMP-4 by explants of amnion $(A)$, chorion $(C)$, placenta $(P)$ and decidua parietalis $(D)$, collected at elective caesarean section at term and maintained in culture for $24 \mathrm{~h}$. b) TIMP-4 in amniotic fluid collected after elective caesarean section (c/s) and spontaneous delivery (svd). Molecular mass markers $(\mathrm{mw})$ are as indicated $(\mathrm{kDa})$.

secreted all four TIMPs (Fig. 4). Immunoblot analysis revealed TIMP-1 as a single broad band at $30 \mathrm{kDa}$, TIMP-2 as a single band (at $28 \mathrm{kDa}$, thus demonstrating different mobility under these reducing conditions when compared with non-reducing conditions of reverse zymography, Fig. 3c), TIMP-3 as two bands as predicted at 24 and $28 \mathrm{kDa}$, corresponding to the unglycosylated and glycosylated forms, and TIMP-4 as a single band at $28 \mathrm{kDa}$. Overall, explants of chorion laeve, decidua and placenta consistently secreted greater amounts of TIMPs than did amnion (Fig. 3a).

The TIMP activity and protein outputs from cultured trophoblast and fibroblast cells of chorion laeve were examined by reverse zymography (Fig. 3b,c) and immunoblot (Fig. 5). Both trophoblast and fibroblast cells secreted TIMP-1 in similar amounts when controlled for cell number. TIMP-2 was secreted by trophoblast cells, with barely detectable production by fibroblast cells. TIMP-3 was secreted solely by trophoblast cells and was detected as two bands corresponding to the unglycosylated and glycosylated forms. TIMP-4 was released predominantly by trophoblast cells, with very low levels of release from fibroblasts. Interestingly, a further two bands at approximately $20-22 \mathrm{kDa}$ were also detected using the TIMP-3 and TIMP-4 antibodies. The precise nature of these bands remains to be elucidated, but they may be products of proteolytic cleavage of these TIMPs.

\section{Localisation of TIMPs}

Representative photomicrographs demonstrating the immunolocalisation of TIMPs $-1,-2,-3$ and -4 in 

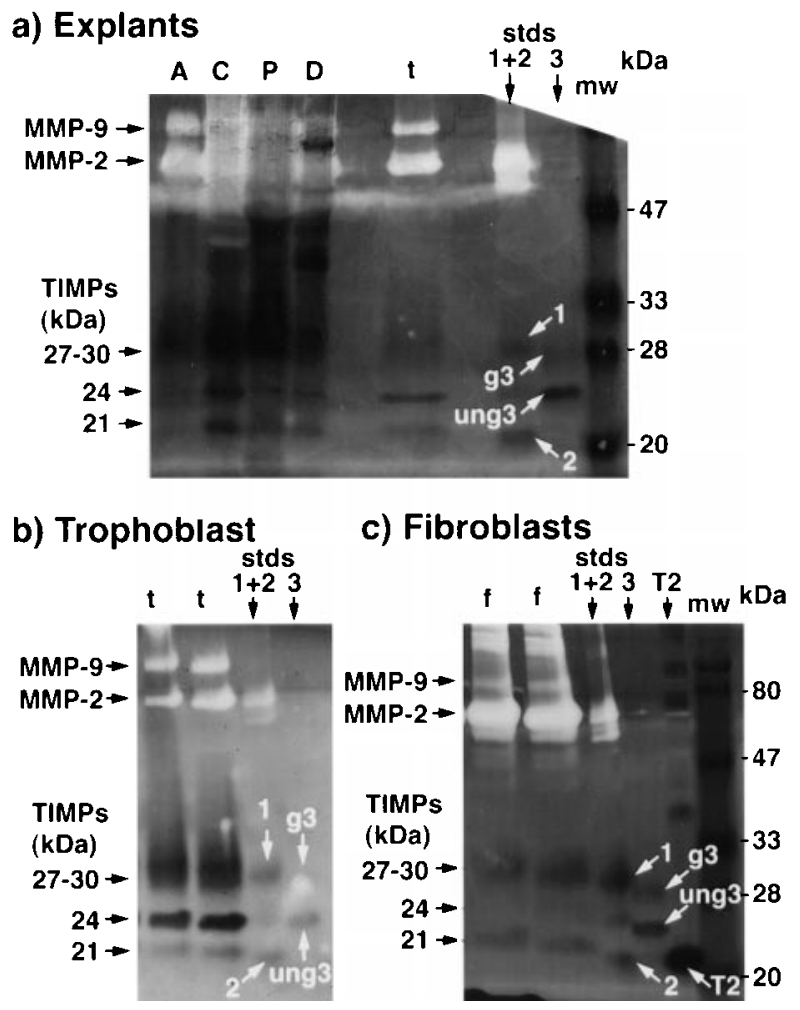

Figure 3 Reverse zymography gels demonstrating the secretion of TIMPs (visualised as darker bands) into culture medium. a) Secretion by explants of amnion $(A)$, chorion $(C)$, placenta $(P)$ and decidua parietalis (D) collected from the myometrial aspect. Three predominant bands of TIMP activity are observed at 27-30 kDa, $24 \mathrm{kDa}$ and $21 \mathrm{kDa}$. b) Secretion by trophoblast cells (t) from chorion laeve. c) Secretion by fibroblast cells (f) from chorion laeve. The standards (stds) of TIMP-1 and TIMP-2 $(1+2 ;$ TIMP-1 as a broad band at 27-30 kDa; TIMP-2 at $21 \mathrm{kDa}$ ) and TIMP-3 (3; gycosylated TIMP-3 at 28-30 kDa and unglycosylated TIMP-3 form at $24 \mathrm{kDa}$ ) are indicated by arrows. Recombinant TIMP-2 (T2) examined in parallel. Molecular mass (mw) standards are identified $(\mathrm{kDa})$. White (clear) bands of gelatinase activity observed at $72 \mathrm{kDa}$ and $92 \mathrm{kDa}$ are MMP-2 and MMP-9, respectively.

placenta, decidua and fetal membranes are shown in Fig. 6. The specificities of the antibodies used to localise TIMPs using immunohistochemical techniques were confirmed by immunoblot analysis as described above, with all antibodies recognising proteins at the predicted molecular weights (Fig. 4). There were no apparent differences in localisation or intensity of any TIMP family members in tissues collected at elective caesarean section when compared with active labour. All negative control sections exhibited no staining (for representative section, see Fig. 6J).

Amnion TIMPs-1, $-2,-3$ and -4 were localised in some individual cells of the amnion epithelium and also in

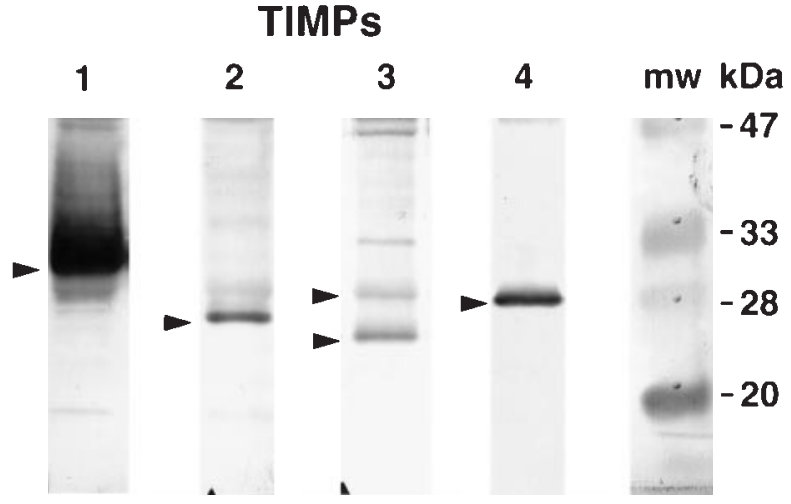

Figure 4 Characterisation, by immunoblot analysis, of TIMP-1, TIMP-2, TIMP-3 and TIMP-4 (1, 2, 3 and 4, respectively) secretion by explants of chorion laeve. Molecular mass markers (mw) are indicated $(\mathrm{kDa})$.

some subepithelial mesenchyme fibroblast cells (Fig. 6C, F, I, M). TIMP-1 was only weakly associated with immunostaining of extracellular matrix. Strikingly, TIMPs-2, -3 and -4 were intensely localised to and consistently in association with extracellular matrix, especially immediately underlying the epithelial basement membrane.

Chorion laeve All four TIMP family members were localised in the cytoplasm of some, but not all, trophoblast cells of the trophoblast layer (Fig. 6C, F, I, M). It was clear from adjacent and parallel sections that trophoblast cells contain immunoreactivity localised in the cytoplasm for more than one TIMP. This co-localisation was replicated both in cells of the decidua parietalis and in syncytiotrophoblasts of the placenta, as discussed below. Furthermore, distribution in trophoblast cells of the immunoreactivity for all these TIMPs was heterogeneous in strips of membranes from the same patient. In the reticular layer of chorion, all TIMPs were present in the cytoplasm of some cells of fibroblast morphology. As in amnion, TIMPs-2, -3 and -4 , but not TIMP-1, were localised to extracellular matrix. Also, TIMP-3 immunoreactivity was present most intensely in association with the extracellular matrix

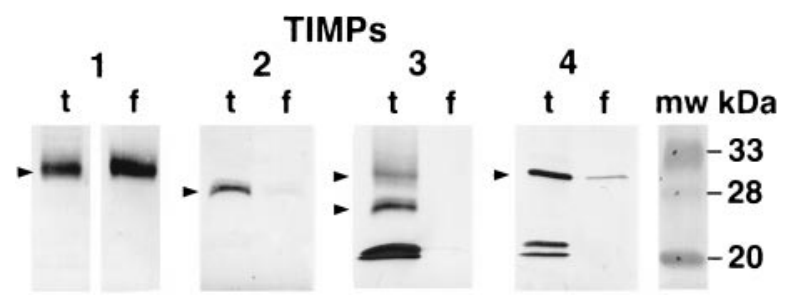

Figure 5 Characterisation, by immunoblot analysis, of secretion of TIMP-1, TIMP-2, TIMP-3 and TIMP-4 (1, 2, 3 and 4, respectively) by trophoblast cells $(\mathrm{t})$ and fibroblast cells $(\mathrm{f})$ of chorion laeve. Molecular mass markers $(\mathrm{mw})$ are as specified $(\mathrm{kDa})$. 

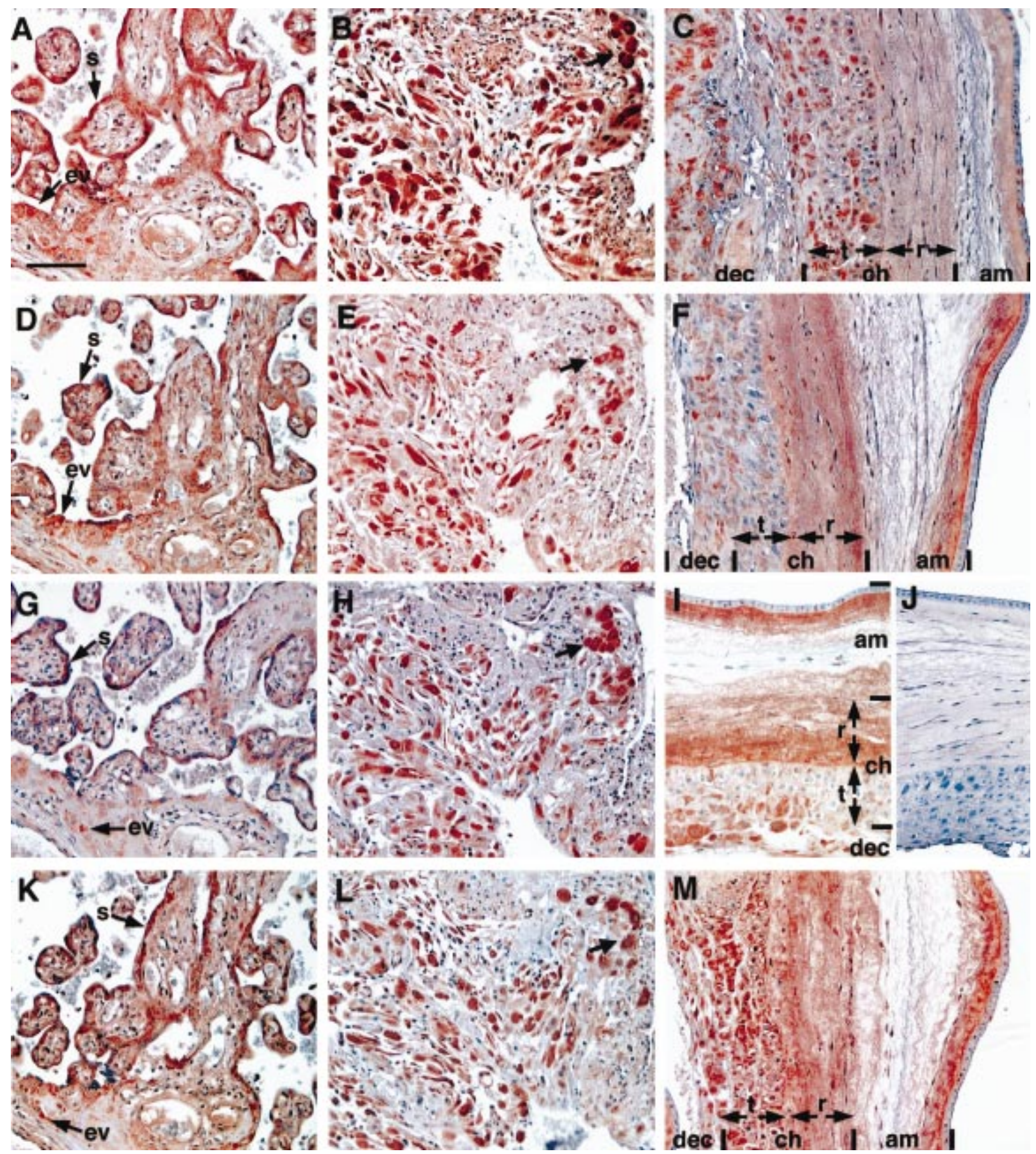

Figure 6 Localisation by immunohistochemistry of TIMP-1 (plates A, B, C), TIMP-2 (D, E, F), TIMP-3 (G, H, I) and TIMP-4 (K, L, M) in sections of placenta $(A, D, G, K)$, decidua collected from the myometrial aspect $(B, E, H, L$; a cluster of cells is identified in these adjacent sections by an arrow showing colocalisation of all TIMPs), and fetal membranes with adherent decidua (C, F, I, M). J is a representative negative control section of fetal membranes (parallel to I), showing no non-specific staining. am, amnion; ch, chorion laeve; dec, decidua parietalis; ev, extravillous trophoblast; $r$, reticular layer of chorion laeve; s, syncytiotrophoblast; $t$, trophoblast cell layer of chorion laeve. All photomicrographs are at the same magnification: bar (in plate A) represents $100 \mu \mathrm{m}$. 
immediately adjacent to the basement membrane that separates the trophoblast from the reticular layer.

Decidua parietalis All TIMPs were present in a majority of cells of the decidua parietalis adherent to cells of chorion laeve trophoblast (Fig. 6C, F, I, M) and also collected from the myometrial aspect (Fig. 6B, E, H, L). It appears that all four TIMPs co-localised within a population of cells (clearly identified in cells marked by arrows on Fig. 6) as observed in parallel adjacent sections, and that this co-localisation was extensive throughout the tissue. Morphologically, these cells appear to be decidualised stromal cells, although the cell types have not been further characterised using specific markers. Unlike the findings with amnion and chorion, localisation of the TIMPs to the extracellular matrix was less apparent.

Placenta All four TIMP family members were clearly immunolocalised throughout the cytoplasm of the syncytiotrophoblast layer (Fig. 6A, D, G, K). Furthermore, immunoreactivity to all four TIMPs was present in the majority of extravillous trophoblast cells both at villous sites and overlying the decidua basalis of the placental bed. In villous core tissues, immunoreactive TIMPs- 1 and -2 were localised in endothelial cells of the fetal capillary and vascular tissues of villi. Immunoreactivity to TIMPs-2 and -4 was also distributed apparently bound to extracellular matrix within chorionic villi. In the decidua basalis, all TIMPs were localised in cells having decidualised stromal-like morphology.

\section{Discussion}

These studies demonstrate a decrease in secretion of TIMPs into the amniotic fluid during active labour. The chorion laeve of the fetal membranes and decidua parietalis secrete TIMPs-1, $-2,-3$ and -4 activity and represent the probable major source of these TIMPs in amniotic fluid and at the feto-maternal interface. The decrease in TIMP activity in amniotic fluid that was collected after the onset of labour suggested that membrane breakdown and detachment of fetal tissues from the uterus involve a withdrawal of endogenous inhibition of tissue MMPs.

Obtaining an absolute measure of TIMP activities is difficult, because the reverse zymography technique allows only relative intensities of TIMP activities to be established (Martelli et al. 1993). Because of the lack of suitable standard preparations of purified or recombinant and standardised TIMPs, it is not possible to quantitate precise values of TIMPs secreted. The presence of SDS, which will dissociate any TIMPs bound to MMPs, means that these techniques measure the total amount of TIMPs. Nevertheless, this combination of reverse zymography with immunoblot analysis has permitted TIMPs to be identified and changes in secretion to be demonstrated.
We consider that the amniotic fluid samples obtained at elective caesarean section and at spontaneous delivery are comparable, as they were collected from the same compartment, namely the hind bag, and are representative of local secretion into this compartment before and during labour.

The fetal membranes have a relatively complicated architecture (Bourne 1962). In an attempt to define further the cellular origins of the various TIMPs, we have used immunohistochemistry and enriched cell cultures. Chorion laeve and decidua parietalis are the major sites of secretion of TIMP activities at the feto-maternal interface at term and secrete TIMPs-1, $-2,-3$ and -4 , as shown by the output from explants. Trophoblast cells of chorion laeve secrete all TIMP forms, whereas chorionic fibroblasts secrete predominantly TIMPs-1 and -2 . All four TIMPs were localised in the chorion laeve and decidua parietalis and amnion, but because TIMPs are secreted, immunohistochemistry is unable to identify the cellular site of production. TIMPs were also localised selectively and specifically to non-cellular sites. Intense immunostaining for TIMPs-2, -3 and -4 was associated with extracellular matrix underlying the basement membrane of the amniotic epithelium, and TIMP-3 with the extracellular matrix of the reticular layer overlying the basement membrane that overlies the trophoblast layer of chorion. This localisation of TIMPs potentially can regulate the spatial breakdown of extracellular matrix by MMPs (Das et al. 1997, Huppertz et al. 1998). However, the functional significance of these current observations is unknown and requires further investigation, but may permit specific local control of tissue remodelling.

The origin of TIMPs in the amniotic fluid is unclear. Explants of chorio-decidua and decidua parietalis consistently secrete more TIMP activity and protein than amnion on a weight-specific basis, and all known TIMPs are localised in these tissues. Although the amnion certainly expresses message for TIMPs-1 and -2 (Rowe et al. 1997), it would appear that the chorion laeve and decidua parietalis are major sites of uterine TIMP secretion throughout pregnancy, because during the first trimester the extra-embryonic coelomic fluid contains all four TIMP family members, whereas levels are low or undetectable in the amniotic fluid (Riley et al. 1999). Also, the secretion of TIMPs by the decidua is similar to that secreted by the non-pregnant endometrium (Zhang \& Salamonsen 1997). It is possible that TIMPs secreted by the chorion and decidua diffuse across the fetal membranes to enter the amniotic fluid. As the extra-embryonic coelomic cavity is obliterated by fusion of the membranes, so the amount of TIMP in amniotic fluid increases (Riley et al. 1999).

The physiological function of TIMP in the amniotic fluid is not known, but it is possible to speculate that they are involved in maintaining the integrity of the fetal membranes, and perhaps the adjacent cervix. Equally, TIMPs present in the amniotic fluid may simply be a pool 
of accumulated protein that was secreted primarily to act elsewhere. We have demonstrated a decline in amniotic fluid TIMP activity in association with labour. At the same time the activity of MMP-9 increases in amniotic fluid and in tissues at term and preterm (Draper et al. 1995, Vadillo-Ortega et al. 1995, 1996, Athayde et al. 1998). The net effect is likely to be breakdown of connective tissue in the fetal membranes (Bryant-Greenwood \& Yamamoto 1995). It has been shown that the collagen content of fetal membranes correlates with the duration of time until rupture (Vadillo-Ortega et al. 1990). Furthermore, the site of membrane rupture is structurally weakened, and changes suggest dissociation and digestion of collagen (Malak \& Bell 1994).

The placenta also represents a major site of TIMP secretion, as demonstrated by the high outputs from explants. Immunolocalisation has shown that all four forms are present in syncytiotrophoblast and placental bed and stem villi extravillous trophoblasts. The placenta may represent the principal source of the increasing concentrations of TIMP-1 in maternal blood during pregnancy (Clark et al. 1994). TIMPs play an important part in regulation of tissue invasion in the establishment of appropriate blood flow into the placental bed (Damsky et al. 1994, Shimonowitz et al. 1994, Lala \& Hamilton 1996, Zhou et al. 1997). TIMPs-1, -2 and -3 are expressed by extravillous trophoblasts (Hurskainen et al. 1996, Ruck et al. 1996) and the balance between MMP-9 and TIMP-3 is important in regulating the invasion of trophoblasts (Das et al. 1997). With the progression of pregnancy, the high level of secretion of TIMP by the placenta is involved in halting this invasion, maintaining tissue integrity and preventing inappropriate tissue breakdown (Huppertz et al. 1998).

The TIMPs may also have other roles at the fetomaternal interface and placenta, besides the regulation of tissue remodelling. TIMP-1 has homology to granulocyte macrophage colony stimulating factor, and can stimulate proliferation and growth directly in other cell systems (Hayakawa et al. 1994, Corcoran \& Stetler-Stevenson 1996). A complex of TIMP-1 with procathepsin-L also stimulates steroidogenesis in testis (Boujrad et al. 1995) and may be involved in the paracrine regulation of oestrogen and progesterone by the fetal membranes and decidua parietalis. In addition, the presence of TIMPs serves to prevent metalloproteinases from activating cytokines such as TNFa (McGeehan et al. 1994), inhibits the release of stimulatory signals bound to the extracellular matrix by metalloproteinase (Lala \& Hamilton 1996), and alters cellular signalling through preventing uncoupling of cellular-matrix interactions (Cross et al. 1994, Damsky et al. 1994).

These studies demonstrate that there is secretion of large quantities and a broad range of TIMPs at the end of pregnancy, by the fetal membranes, decidua and placenta. During active labour, there is a decrease in the amount of
TIMPs secreted into amniotic fluid. This suggests a local control of production of TIMPs, which may be important for breakdown of the fetal membranes and the fetomaternal interface, and for cervical ripening. TIMPs may also participate in a range of paracrine actions at the feto-maternal interface that are involved in the initiation and maintenance of labour.

\section{Acknowledgements}

This study was funded by the Scottish Hospital Endowment's Research Trust (project 1389). We would like to thank Dr Euan Wallace and Dr Janet Brennand for supplying some of the amniotic fluid samples.

\section{References}

Athayde N, Edwin SS, Romero R, Gomez R, Maymon E, Pacora P \& Menon R 1998 A role for matrix metalloproteinase-9 in spontaneous rupture of the fetal membranes. American Journal of Obstetrics and Gynecology 179 1248-1253.

Boujrad N, Ogwuegbu SO, Garnier M, Lee CH, Martin BM \& Papadopoulos V 1995 Identification of a stimulator of steroid hormone synthesis isolated from testis. Science 268 1609-1612.

Bourne G 1962 The structure of the amnion. In Human Amnion and Chorion, pp 4-11. London: Lloyd-Luke.

Brennand JE, Leask R, Kelly RW, Greer IA \& Calder AA 1995 Changes in prostaglandin synthesis and metabolism associated with labour, and the influence of dexamethasone, RU486 and progesterone. European Journal of Endocrinology 133 527-533.

Bryant-Greenwood GD \& Yamamoto SY 1995 Control of peripartal collagenolysis in the human chorio-decidua. American Journal of Obstetrics and Gynecology 172 63-70.

Clark IM, Morrison JJ, Hackett GA, Powell EK, Cawston TE \& Smith SK 1994 Tissue inhibitor of metalloproteinases: serum levels during pregnancy and labour term and preterm. Obstetrics and Gynecology 83 532-537.

Corcoran ML \& Stetler-Stevenson WG 1996 Tissue inhibitor of metalloproteinases-2 (TIMP-2) stimulates fibroblast proliferation via a cyclic adenosine 3'5'-monophosphate (cAMP)-dependent mechanism. Journal of Biological Chemistry 270 13453-13459.

Cross JC, Werb Z \& Fisher SJ 1994 Implantation and the placenta: key pieces of the development puzzle. Science 266 1508-1518.

Damsky CH, Fitzgerald ML \& Fisher SJ 1994 Distribution patterns of extracellular matrix components and adhesion receptors are intricately modulated during first trimester cytotrophoblast differentiation along the invasive pathway, in vivo. Journal of Clinical Investigation 89 210-222.

Das SK, Yano S, Wang J, Edwards DR, Nagase H \& Dey SK 1997 Expression of matrix metalloproteinases and tissue inhibitors of metalloproteinases in the mouse uterus during the peri-implantation period. Developmental Genetics 21 44-54.

Draper D, McGregor J, Hall J, Jones W, Beutz M \& Heine RP 1995 Elevated protease activities in human amnion and chorion correlate with preterm premature rupture of membranes. American Journal of Obstetrics and Gynecology 173 1506-1512.

Goldenberg RL, Mercer BM, Iams JD, Moawad AH, Meis PJ \& Das A 1997 The preterm prediction study: patterns of cervicovaginal fetal fibronectin as predictors of spontaneous preterm delivery. National Institute of Child Health and Human Development Maternal-Fetal Medicines Units Network. American Journal of Obstetrics and Gynecology 177 8-12. 
Hampton AL, Butt AR, Riley SC \& Salamonsen LA 1995 Tissue inhibitors of metalloproteinases in endometrium of ovariectomised, steroid-treated ewes and during the estrous cycle and early pregnancy. Biology of Reproduction 53 302-311.

Hayakawa T, Yamashita K, Ohuchi E \& Shinagawa A 1994 Cell growth-promoting activity of tissue inhibitor of metalloproteinases-2 (TIMP-2). Journal of Cell Science 107 2373-2379.

Hulboy DL, Rudolph LA \& Matrisian LM 1997 Matrix metalloproteinases as mediators of reproductive function. Molecular Human Reproduction 3 27-45.

Huppertz B, Kertschanska S, Demir AY, H-G \& Kaufmann P 1998 Immunohistochemistry of matrix metalloproteinases (MMP), their substrates, and their inhibitors (TIMP) during trophoblast invasion in the human placenta. Cell and Tissue Research 291 133-148.

Hurskainen T, Höyhtyä M, Tuuttila A, Oikarinen A \& AutioHarmainen H 1996 mRNA expressions of TIMP-1, -2, and -3 and 92-KD type IV collagenase in early human placenta and decidual membrane as studied by in situ hybridisation. Journal of Histochemistry and Cytochemistry 44 1379-1388.

Kelly RW, Carr G \& Riley SC 1997 The inhibition of synthesis of a $\beta$-chemokine, monocyte chemotactic protein (MCP-1) by progesterone. Biochemical and Biophysical Research Communications $239557-561$.

Lala PK \& Hamilton GS 1996 Growth factors, proteases and protease inhibitors in the maternal--fetal dialogue. Placenta 17 545-555.

Lei H, Vadillo-Ortega F, Paavola LG \& Strauss JF 199592 kDa gelatinase (matrix metalloproteinase-9) is induced in rat amnion immediately prior to parturition. Biology of Reproduction 53 339-344.

McGeehan GM, Becherer JD \& Bast RC 1994 Regulation of tumour necrosis factor-alpha processing by a metalloproteinase inhibitor. Nature 370 558-561.

Malak TM \& Bell SC 1994 Structural characteristics of term human fetal membranes: a novel zone of extreme morphological alteration within the rupture site. British Journal of Obstetrics and Gynaecology 101 375-386.

Malak TM, Sizmur F, Bell SC \& Taylor DJ 1996 Fetal fibronectin in cervicovaginal secretions as a predictor of preterm birth. British Journal of Obstetrics and Gynaecology 103 648-653.

Martelli M, Campana A \& Bischof P 1993 Secretion of matrix metalloproteinases by human endometrial cells in vitro. Journal of Reproduction and Fertility 98 67-76.

Parry S \& Strauss JF 1998 Premature rupture of the fetal membranes. New England Journal of Medicine 338 663-670.

Riley SC, Walton JC, Herlick JM \& Challis JRG 1991 The localization and distribution of corticotropin-releasing hormone in the human placenta and fetal membranes throughout gestation. Journal of Clinical Endocrinology and Metabolism 72 1001-1007.

Riley SC, Leask R, Howe DC \& Calder AA 1996 Secretion of matrix metalloproteinases (MMP) -2 and -9 by human fetal membranes and decidua at term prior to and during active labour. Journal of Reproduction and Fertility (Abstract) 179.

Riley SC, Leask R, Chard T, Wathen NC, Calder AA \& Howe DC 1999 Secretion of matrix metalloproteinase-2, matrix metalloproteinase- 9 and tissue inhibitor of metalloproteinases into the intrauterine compartments during early pregnancy. Molecular Human Reproduction 5 376-381.

Rowe TF, King LA, Macdonald PC \& Casey ML 1997 Tissue inhibitor of metalloproteinase-1 and tissue inhibitor of metalloproteinase-2 expression in human amnion mesenchymal and epithelial cells. American Journal of Obstetrics and Gynecology 176 915-921.

Ruck P, Marzusch K, Horny H-P, Dietl J \& Kaiserling E 1996 The distribution of tissue inhibitor of metalloproteinases-2 (TIMP-2) in the human placenta. Placenta 17 263-266.

Shimonovitz S, Hurwitz A, Dushnik M, Anteby E, Geva-Eldar T \& Yagel S 1994 Developmental regulation of the expression of 72 and $92 \mathrm{kDa}$ type IV collagenases in human trophoblasts: a possible mechanism for control of trophoblast invasion. American Journal of Obstetrics and Gynecology 171 832-838.

Vadillo-Ortega F, Gonzalez-Avila G, Karchmer S, Cruz NM, Ayala-Ruiz A \& Lama MS 1990 Collagen metabolism in premature rupture of amniotic membranes. Obstetrics and Gynecology 75 84-88.

Vadillo-Ortega F, Gonzalez-Avila G, Furth EE, Lei H, Muschel RJ, Stetler-Stevenson WG \& Strauss JF 1995 92-kd type IV collagenase (matrix metalloproteinase-9) activity in human amniochorion increases with labor. American Journal of Pathology 146 148-156.

Vadillo-Ortega F, Hernandez A, Gonzalez-Avila G, Bermejo L, Iwata K \& Strauss JF 1996 Increased matrix metalloproteinase activity and reduced tissue inhibitor of metalloproteinases-1 levels in amniotic fluids from pregnancies complicated by premature rupture of membranes. American Journal of Obstetrics and Gynecology 174 $1371-1376$.

Waterhouse P, Denhardt DT \& Khoka R 1993 Temporal expression of tissue inhibitors of metalloproteinases in mouse reproductive tissues during gestation. Molecular Reproduction and Development 35 219-226.

Zhang J \& Salamonsen LA 1997 Tissue inhibitor of metalloproteinases (TIMP) $-1,-2$ and -3 in human endometrium during the menstrual cycle. Molecular Human Reproduction 3 735-741.

Zhou Y, Fisher SJ, Janatpour M, Genbacev O, Dejana E, Wheelock M \& Damsky CH 1997 Human cytotrophoblasts adopt a vascular phenotype as they differentiate. A strategy for successful endovascular invasion? Journal of Clinical Investigation 99 2139-2151.

Received 10 February 1999

Accepted 26 April 1999 